\title{
An audit of cyclosporin for systemic lupus erythematosus and related overlap syndromes: limitations of its use
}

\author{
S J Morton, R J Powell
}

\begin{abstract}
Objective-To establish the usefulness of cyclosporin for systemic lupus erythematosus (SLE) in a routine clinical setting. Methods-Patients who had received cyclosporin for SLE, mixed connective tissue disease, and other overlap syndromes were identified. Data relating to treatment with cyclosporin, including dosage, concurrent steroid use, response to treatment, side effects, and reasons for withdrawal, were extracted from medical notes.

Results-A total of 43 patients had been treated with cyclosporin between 1995 and 1998. Cyclosporin, average dose $4 \mathrm{mg} / \mathrm{kg} / \mathrm{d}$, was started in patients whose disease was active despite previous use of alternative second line agents. On every occasion when cyclosporin was used for thrombocytopenia the response was good, but when arthritis was the indication, the response was good in 14/26. The success rates for symptoms of arthralgia, myalgia, and fatigue were lower. Side effects occurred in $28 / 43(65 \%)$ cases, and on $39 / 47$ $(83 \%)$ occasions cyclosporin was withdrawn owing to either side effects or failure to control disease activity, after a median duration of treatment of only four months.

Conclusions-The response to cyclosporin is mixed and usually short lived. (Ann Rheum Dis 2000;59:487-489)
\end{abstract}

Small open studies of cyclosporin in lupus nephritis have yielded promising results, though the earliest of these, in 1981, ${ }^{1}$ highlighted the problem of side effects when large doses of cyclosporin - that is, $10 \mathrm{mg} / \mathrm{kg} / \mathrm{d}$ were used. Since then most studies ${ }^{2-8}$ have been based upon the use of lower doses of cyclosporin - for example, $5 \mathrm{mg} / \mathrm{kg} / \mathrm{d}$, and side effects, though common, have been less severe or controllable with drugs - for example, antihypertensive drugs. This study examined the use of cyclosporin for a variety of lupus manifestations in a routine clinical setting.

Methods

All patients with systemic lupus erythematosus (SLE), mixed connective tissue disease (MCTD), and other SLE overlap syndromes who had received cyclosporin while attending the clinical immunology clinics at Nottingham University Hospital were identified. The patients with SLE fulfilled the 1982 revised criteria of the American College of Rheumatology for the diagnosis of SLE. ${ }^{9}$ Data relating to the diagnosis, demographic details, and previous second line agents were extracted from medical notes. The following cyclosporin treatment details were recorded:

- Dates of starting, and if relevant, stopping cyclosporin

- Duration of treatment with cyclosporin if stopped before December 1998

- Cyclosporin dose; starting dose, maximum dose, mean dose, and cumulative dose

- Adjunctive use of steroids, including the dosage

- Original indication for treatment

- Level of disease activity at the start of treatment; partial remission or active

- Response to treatment

- Side effects

- Reasons for withdrawal.

Response to treatment was classified, as one of the following:

- Good response $=$ complete/near complete resolution of symptom/sign during treatment

- Slight improvement = probable improvement, but not complete resolution of symptom/sign

- Unchanged = no improvement or deterioration at any stage during treatment

- Worsened = never any improvement, condition deteriorated from the outset.

For the subgroup of patients in partial remission at the start of treatment with cyclosporin a "good response" was defined as further improvement or the ability to reduce steroid dosage without incurring a flare, or both. For three patients with renal lupus the response could not be ascertained because of a lack of information in the notes.

\section{Results}

Forty patients with SLE, one with an SLE/ Sjögren's overlap syndrome, and two with MCTD were treated with cyclosporin for three years from December 1995. Cyclosporin was used on more than one occasion in some patients, and therefore the total number of treatments was 49. Table 1 shows the demographic features.

All patients had been treated with one or more second line drugs before cyclosporin: 11 had received one other drug, five patients had been given two drugs, and 27 patients three or more, including hydroxychloroquine, azathioprine, methotrexate, intravenous immunoglobulin, chlorambucil, and pulse IV cyclophosphamide (in 21/43). In $37 / 49$ cases cyclosporin was started in patients whose
Accepted for publication 28 January 2000 
disease had flared while receiving an alternative second line agent or no treatment at all. In $12 / 49$ it was given to patients in whom a degree of disease control had been achieved first with either steroids, cyclophosphamide or, in one case, with azathioprine (which had induced thrombocytopenia). The indications for which it was considered necessary to give steroids or cyclophosphamide first were thrombocytopenia (three cases), cerebral lupus (one), vasculitis (three), arthritis (three), and renal lupus (one).

DURATION OF CYCLOSPORIN TREATMENT

The duration of treatment ranged from 7 to 768 days. The median was 109 days (four months), interquartile range 49-287 days. The duration was $<1$ month in $8 / 49$ cases $(16 \%)$, $1-6$ months in $25 / 49$ (51\%), 6-12 months in $7 / 49(14 \%), 1-2$ years in $8 / 49(16 \%)$, and $>2$ years in $1 / 49(2 \%)$.

DRUG DOSAGE

The dose of cyclosporin used was calculated in units of $\mathrm{mg} / \mathrm{kg} /$ day. The data below therefore apply to 46 cyclosporin uses as in three instances the weight was not available:

- Mean starting dose $3.5 \mathrm{mg} / \mathrm{kg} /$ day (range $1.9-6.5 \mathrm{mg} / \mathrm{kg} /$ day)

- Mean average dose $4.1 \mathrm{mg} / \mathrm{kg} /$ day (1.5-6.5 $\mathrm{mg} / \mathrm{kg}$ /day)

- Mean maximum dose $4.8 \mathrm{mg} / \mathrm{kg} /$ day (2.9 $7.3 \mathrm{mg} / \mathrm{kg} /$ day).

In all cases dosage was dictated by clinical response, side effects, and recommended trough levels (95-205 ng/ml).

On 32/49 (67\%) occasions prednisolone was given concurrently with cyclosporin. In 14/32 $(44 \%)$ of cases it was used for the duration of the cyclosporin treatment, in $4 / 32(13 \%)$ of cases it was given for $<25 \%$ of the time, in $7 / 32$ $(22 \%)$ for $25-49 \%$ of the time, and in a further $7 / 32(22 \%)$ for $50-99 \%$ of the time. Reductions in the dose of prednisolone during the course of cyclosporin treatment, to $50 \%$ or less of the starting dose, were made in $17 / 31$ (55\%) cases. On 14/31 occasions when prednisolone was used, the mean dose of prednisolone was $<10 \mathrm{mg}$. In 13/49 occasions IV methylprednisolone, $0.5-3 \mathrm{~g}$, was given in pulses over one to five days at the start of treatment.

Table 1 Demographic details of patients with systemic lupus erytematosus

\begin{tabular}{ll}
\hline Demographic details & \\
\hline No of patients (uses of cyclosporin) & $43(49)$ \\
Median age (years, interquartile range) & $34(25-43)$ \\
Sex ratio (F:M) & $41: 2$ \\
Race & \\
White & 32 \\
Oriental & 3 \\
Asian & 3 \\
Negro & 2 \\
Mixed† & 3 \\
Median disease duration (years, interquartile & $7(2.5-12.0)$ \\
range) & \\
\hline
\end{tabular}

${ }^{\star}$ White $=$ British, Mediterranean; Oriental $=$ Chinese, Malay; Asian $=$ Indian, Pakistani, Ugandan $;$ Negro $=$ West Indian $\dagger$ Mixed $=2 \times$ white $/$ negro and $1 \times$ white $/$ Asian.
Table 2 Response to treatment with cyclosporin

\begin{tabular}{lllll}
\hline & & $\begin{array}{l}\text { Slightly } \\
\text { improved }\end{array}$ & Unchanged & Worsened \\
\hline Arthritis & 14 & 6 & 5 & 1 \\
Rash & 4 & 2 & 2 & 2 \\
Arthralgia & 0 & 4 & 4 & 0 \\
Fatigue & 1 & 3 & 2 & 0 \\
Renal & 2 & 0 & 1 & 0 \\
Discoid rash & 1 & 2 & 2 & 1 \\
Vasculitis & 2 & 0 & 1 & 1 \\
Myalgia & 1 & 3 & 1 & 0 \\
Thombocytopenia & 4 & 0 & 0 & 0 \\
Anaemia & 1 & 1 & 0 & 0 \\
Neutropenia & 1 & 0 & 0 & 0 \\
Alopecia & 1 & 0 & 1 & 0 \\
Panniculitis & 0 & 0 & 1 & 0 \\
Serositis & 1 & 0 & 0 & 0 \\
Cerebral lupus & 1 & 0 & 0 & 0 \\
\hline
\end{tabular}

Table 3 Side effects of cyclosporin in 43 patients

\begin{tabular}{ll}
\hline Side effect & Patients (No (\%)) \\
\hline Hypertension & $14(33)$ \\
Renal toxicity & $7(16)$ \\
Gastrointestinal disturbance & $6(14)$ \\
Oedema & $6(14)$ \\
Muscle pain/cramps & $4(9)$ \\
Hirsutism $\ddagger$ & $3(7)$ \\
Headaches & $3(7)$ \\
Infections & $2(5)$ \\
Rash/itch & $2(5)$ \\
Asthma & $1(2)$ \\
General malaise & $1(2)$ \\
Gum hypertrophy/soreness & $1(2)$ \\
\hline
\end{tabular}

* Renal toxicity; in two additional cases (not included in the figures above) a rise in creatinine was seen in association with renal lupus. It was therefore not clear whether cyclosporin was the cause.

†Gastrointestinal disturbance includes nausea, vomiting, abdominal pain, and bloatedness.

$\ddagger$ Hirsutism means hair growth of sufficient severity for the patient to complain.

RESPONSE TO CYCLOSPORIN

Table 2 shows the response to treatment (defined in "Methods") according to the indication(s) for which it was prescribed.

\section{SIDE EFFECTS OF CYCLOSPORIN}

Side effects were common (28/43 (65\%)) and prompted withdrawal in a significant number. Hypertension was defined as $>90 \mathrm{~mm} \mathrm{Hg}$ diastolic, which was persistent and considered severe enough to warrant treatment with antihypertensive drugs. Renal toxicity was defined as a rise in serum creatinine of $>30 \%$ above baseline values. Table 3 shows the incidence of the various side effects.

REASONS FOR WITHDRAWAL

Of the 49 instances when cyclosporin was used, it has been withdrawn in all but two cases. On 39/47 (83\%) occasions cyclosporin was stopped owing to side effects, lack of efficacy, or both. On two other occasions it was stopped owing to poor compliance and pregnancy. In a few instances $(6 / 47(13 \%))$ of it was withdrawn as the patient was considered to be in remission.

\section{Discussion}

The usefulness of cyclosporin with or without steroid treatment, in a routine clinical setting, appears limited by side effects and lack of efficacy. 
Patients in this study had disease at the severe end of the spectrum with 21 (49\%) having had previous treatment with cyclophosphamide, which accords with other open clinical studies. ${ }^{2-8}$ In contrast with previous publications, not all patients (63\%) were receiving concurrent prednisolone, and of those that were receiving them, almost half had mean doses of $<10 \mathrm{mg} / \mathrm{d}$. The response to cyclosporin was mixed for most indications, arthritis responded to treatment about half of the time; fewer patients responded well if the original indication for treatment was rash, arthralgia, myalgia, or fatigue. Haematological abnormalities, particularly thrombocytopenia, improved in most cases, consistent with recent reports of good responses to low doses of cyclosporin. ${ }^{10}{ }^{11}$ Overall, the rates of response to treatment seen in this study are lower than those of several previous studies. ${ }^{3478}$ This may be because the disease manifestation being treated was renal lupus in three of the four specified studies, ${ }^{348}$ in contrast with our patient group who had various manifestations. The method of ascertainment of response in this audit was categorised subjectively based on information available from medical case notes rather than a validated scoring system.

It is arguable that a more valuable end point of success of treatment is not the initial response to treatment but the number of patients in whom a state of clinical remission is achieved and whose treatment can be withdrawn. This is not an end point that has been applied to any of the studies reported to date, with the exception of one, ${ }^{6}$ in which treatment was withdrawn for the above reason in only one of 12 patients (four continued with treatment). In this latter study, cyclosporin was stopped in 9/12 cases because of side effects, lack of efficacy, or a flare in disease after initial response to treatment. These figures are comparable with ours where in 39/47 (83\%) instances cyclosporin was withdrawn owing to side effects or a failure to control disease activity adequately, or both. In only $6 / 47$ instances was the drug withdrawn after clinical remis- sion. In a significant number $(7 / 43(16 \%))$ treatment was stopped before one month, and before six months in 29 (67\%) cases.

\section{Conclusion}

In a routine clinical setting, a proportion of patients with SLE, and closely allied conditions, respond to treatment with cyclosporin (4 $\mathrm{mg} / \mathrm{kg} / \mathrm{d}$ ), but side effects are common and a significant number either fail to respond to treatment from the outset or flare after initial improvement while taking the drug. In most, cyclosporin is withdrawn because of side effects/lack of efficacy and often before completion of six months' treatment (39/47 occasions $(83 \%))$.

We are grateful to Dr Peter Lanyon and Dr Ben Palmer for their statistical advice.

1 Isenberg DA, Snaith ML, Morrow WJW, Al-khader AA, Cohen SL, Fisher C. Cyclosporin A for the treatment of systemic lupus erythematosus. Int J Immunopharmacol 1981;3:163-9.

2 Feutren G, Querin S, Noel H, Chatenoud L, Beaurain G, Tron F, et al. Effects of cyclosporine in severe systemic Tron $\mathrm{F}$, et al. Effects of cyclosporine in severe
lupus erythematosus. J Pediatr 1987;111:1063-8.

3 Favre $\mathrm{H}$, Miescher PA. Huang YP, Chatelanat F, Mihatsch MJ. Cyclosporin in the treatment of lupus nephritis. Am J Nephrol 1989; 9(suppl 1):57-60.

4 Tokuda M, Kurata N, Mizoguchi A, Masayuki I, Seto K, Kinashi M, et al. Effect of low-dose cyclosporin A on systemic lupus erythematosus disease activity. Arthritis Rheum 1994;37:551-8.

5 Miescher PA, Favre H, Lemoine R, Huang Y-P. Drug combination therapy of systemic lupus erythematosus. Springer Semin Immunopathol 1994;16:295-311.

6 Manger K, Kalden JR, Manger B. Cyclosporin A in the treatment of systemic lupus erythematosus: results of an open clinical study. Br J Rheumatol 1996;35:669-75.

7 Caccavo D, Lagana B, Mitterhofer AP, Ferri GM, Afeltra A, Amoroso A, et al. Long-term treatment of systemic lupus erythematosus with cyclosporin A. Arthritis Rheum 1997; 40:27-35.

8 Dostal C, Tesar V, Rychlik I, Zabka J, Vencovsky J, Bartunkova J, et al. Effect of 1 year cyclosporine A reatment on the activity and renal involvement of systemic lupus erythematosus: a pilot study. Lupus 1998;7:29-36.

9 Tan EM, Cohen AS, Fries JF, Masi A, McShane D, Rothfield NF, et al. The 1982 revised criteria for the classification of systemic lupus erythematosus. Arthritis Rheum 1982;25:1271-7.

0 Sugiyama M, Ogasawara H, Kaneko H, Hishikawa T, Iida $\mathrm{N}$, Hashimoto $\mathrm{H}$, et al. Effect of extremely low dose cyclosporine treatment on the thrombocytopenia in systemic lupus erythematosus. Lupus 1998;7:53-6.

11 Sekigawa I, Ogawawara H, Sugiyama M, Kaneko H, Hishikawa T, Tokano Y, et al. Extremely low dose treatment of cyclosporine for autoimmune diseases [letter]. Clin Exp Rheumatol 1998;16:352. 